\title{
POMzites: A Family of Zeolitic Polyoxometalate Frameworks from a Minimal Building Block Library
}

\author{
Thomas Boyd, Scott G. Mitchell, David Gabb, De-Liang Long, Yu-Fei Song, and Leroy Cronin*(i) \\ WestCHEM, School of Chemistry, University of Glasgow, Joseph Black Building, University Avenue, Glasgow G12 8QQ U.K.
}

Supporting Information

ABSTRACT: We describe why the cyclic heteropolyanion $\left[\mathrm{P}_{8} \mathrm{~W}_{48} \mathrm{O}_{184}\right]^{40-}$ (abbreviated as $\left.\left\{\mathrm{P}_{8} \mathrm{~W}_{48}\right\}\right)$ is an ideal building block for the construction of intrinsically porous framework materials by classifying and analyzing $>30$ coordination polymers incorporating this polyoxometalate (POM) ligand. This analysis shows that the exocyclic coordination of first-row transition metals (TMs) to $\left\{\mathrm{P}_{8} \mathrm{~W}_{48}\right\}$ typically yields frameworks which extend through $\{\mathrm{W}-\mathrm{O}-\mathrm{TM}-\mathrm{O}-\mathrm{W}\}$ bridges in one, two, or three dimensions. However, despite the rich structural diversity of such compounds, the coordination of TMs to the $\left\{\mathrm{P}_{8} \mathrm{~W}_{48}\right\}$ ring is poorly understood, and therefore largely unpredictable, and had not until now been present with any structural classification that could allow rational design. Herein, not only do we present a new approach to understand and classify this new class of materials, we also present three $\left\{\mathrm{P}_{8} \mathrm{~W}_{48}\right\}$-based frameworks which complement those frameworks which have previously been described. These new compounds help us postulate a new taxonomy of these materials. This is possible because the TM coordination sites of the $\left\{\mathrm{P}_{8} \mathrm{~W}_{48}\right\}$ ring

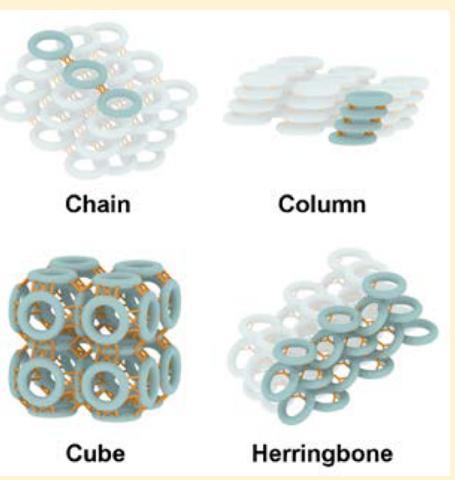
are found, once fully mapped, to lead to well-defined classes of connectivity. Together, analysis provides insight into the nature of the building block connectivity within each framework, to facilitate comparisons between related structures, and to fundamentally unite this family of compounds. Hence we have tentatively named these compounds as "POMzites" to reflect the POM-based composition and zeolitic nature of each family member, although crucially, POMzites differ from zeolites in the modular manner of their preparation. As the synthesis of further POMzites is anticipated, the classification system and terminology introduced here will allow new compounds to be categorized and understood in the context of the established materials. A better understanding of TM coordination to the $\left\{\mathrm{P}_{8} \mathrm{~W}_{48}\right\}$ ring may allow the targeted synthesis of new frameworks rather than the reliance on serendipity apparent in current methods.

\section{INTRODUCTION}

Over the past two decades, the emergence of metal-organic frameworks $(\mathrm{MOFs})^{1,2}$ and covalent organic frameworks $(\mathrm{COFs})^{3,4}$ has reinvigorated the field of crystalline microporous materials, previously dominated by zeolites. However, with widespread applications in areas including, but not restricted to, heterogeneous catalysis, ${ }^{5,6}$ the adsorption of pollutants, ${ }^{7-9}$ and resistant coatings, ${ }^{10,11}$ zeolites are still regarded as the benchmark for functional porous materials. Although the porosity of zeolites and related materials has been exploited for centuries, ${ }^{12,13}$ real insights into the behavior of guest molecules in confined environments, and the role of the host in which they reside, have only recently become possible through advanced crystallographic techniques. ${ }^{14-18}$ Composed primarily of the naturally abundant elements $\mathrm{O}, \mathrm{Si}$, and $\mathrm{Al}$, zeolites have remarkable thermal stability upon evacuation, regular pore sizes, and high acidity. However, tuning zeolite functionality is generally limited to controlling the ratio of $\mathrm{Si} A \mathrm{Al}$ in the framework, ${ }^{19}$ while extensive structure modulation of these otherwise simple inorganic materials relies on the introduction of organic molecules, either as structure-directing agents (SDAs) or as functional organic platforms incorporated within the zeolite scaffold itself. ${ }^{20-22}$
MOF materials, including hybrid zeolite analogues, are born of remarkably sophisticated design principles, and display a richly diverse range of properties. ${ }^{23-25}$ Synthetic control in MOF chemistry is largely attributable to the modular nature of MOF preparation, with secondary building units (SBUs) utilized as geometrically well-defined components to access many of the great variety of framework topologies currently realized. ${ }^{26}$ Despite rapid progress made in this field and the widespread application of MOFs, there remains scope to explore and extend the thermal and chemical stability range of the compounds due to the nature of the organic constituents. Therefore, the development of porous transition metal oxidebased molecular materials could be interesting due to the promise of flexibility and tunable redox, catalytic, and thermal properties. As such, POM-frameworks promise to combine the thermal stability and general applicability of zeolites, combined with the synthetic control and tunable properties of MOFs.

Polyoxometalates (POMs) are a diverse class of early transition metal oxide clusters, typically comprised of multiple $\mathrm{W}, \mathrm{Mo}$, or $\mathrm{V}$ centers connected through shared oxygen atoms, and commonly incorporating additional heteroelements such as

Received: February 21, 2017

Published: April 3, 2017 
$\mathrm{Si}, \mathrm{P}$, or $\mathrm{Ge}^{27-29}$ Although by their definition POMs are discrete (0-D) molecules, the introduction of transition metals (TMs) and/or organic moieties to POM solutions may lead to connectivity between clusters, and their extension into coordinatively linked 1-D chains, 2-D sheets, or 3-D networks. $^{30-33}$

By application of the topological "node and linker" designation given to the structural components of a MOF, in multidimensional inorganic POM assemblies the POM units may be considered as inorganic nodes, which extend into infinite lattice arrangements through the coordination of TM linkers. However, in contrast to MOFs, it is primarily the versatility of the node, and not the linker, which generates the diversity of structures found in TM-linked POM framework materials. Like MOFs, these purely inorganic networks have been shown to exhibit tunable properties through rational synthetic strategies. ${ }^{35,36}$ Furthermore, the recent trend for the incorporation of POM guests inside porous frameworks recognizes the acidic, electronic, and catalytic properties that these clusters may embellish on the overall framework structure. ${ }^{37-40}$ It is therefore clear that the direct incorporation of POMs into porous framework scaffolds is a valid strategy for the modular synthesis of robust functional materials, without the need for an organic component.

Two main strategies are typically employed in the construction of modular frameworks with high porosity: (1) the selection of long, narrow linkers (which may lead to the interpenetration of multiple frameworks), and (2) the prefabrication of a pore within one of the components. The latter approach is most commonly adopted to incorporate POMs within porous framework scaffolds, since these clusters often assume cyclic configurations. ${ }^{41}$ In particular, the crown-type heteropolyanion, $\left[\mathrm{P}_{8} \mathrm{~W}_{48} \mathrm{O}_{184}\right]^{40-}$ (hereafter referred to as $\left.\left\{\mathrm{P}_{8} \mathrm{~W}_{48}\right\}\right)$ is notable for several properties, including its highnegative charge and remarkable electrochemistry. ${ }^{42,43}$ Its intrinsic nanometer-sized cavity means $\left\{\mathrm{P}_{8} \mathrm{~W}_{48}\right\}$ is an ideal candidate to be utilized as a network synthon, to prepare open framework materials with microporosity (Figure 1). ${ }^{44}$ Such structures have already been prepared by introducing first-row TMs to aqueous solutions of $\left\{\mathrm{P}_{8} \mathrm{~W}_{48}\right\}$; however, the desired control in preparing $\left\{\mathrm{P}_{8} \mathrm{~W}_{48}\right\}$-based porous frameworks is yet to be realized. .5,46 $^{\text {. }}$

Detailed herein are the syntheses of three coordinatively linked framework structures, based on the minimal building
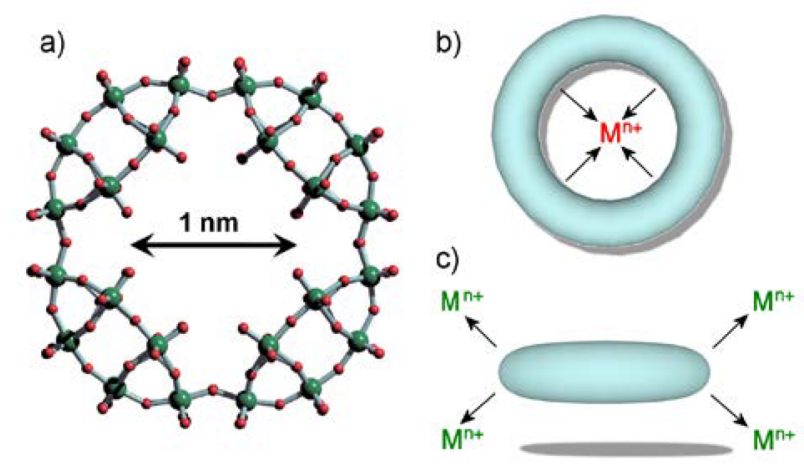

Figure 1. (a) Nanoporous $\left[\mathrm{P}_{8} \mathrm{~W}_{48} \mathrm{O}_{184}\right]^{40-}$ structure, with simplified ring representation showing both (b) endocyclic (red) and (c) exocyclic (green) coordination of transition metals. Dark green spheres, W; red spheres, $\mathrm{O}$; light blue rings, $\left[\mathrm{P}_{8} \mathrm{~W}_{48} \mathrm{O}_{184}\right]^{40-34}$ block library of $\left\{\mathrm{P}_{8} \mathrm{~W}_{48}\right\}$ nodes and TM linkers. In addition, the TM coordination sites of $\left\{\mathrm{P}_{8} \mathrm{~W}_{48}\right\}$ are fully mapped, allowing a comprehensive analysis of ring connectivity within the known $\left\{\mathrm{P}_{8} \mathrm{~W}_{48}\right\}$-based frameworks. The term "POMzites" is introduced to apply to this unified class of materials, alluding both to their POM-based constituents and to their zeolitic nature. Despite the various similarities between POMzites and zeolites in terms of their composition and properties, the two compound families are accessed via contrasting routes of assembly. As described here, POMzites are prepared in a modular fashion, whereas the synthesis of zeolites typically follows a one-pot methodology. The modular nature of POMzite preparation affords a valuable synthetic handle to exert greater control over the eventual framework topologies, which could enable the precise tuning of these porous inorganic materials toward tailored applications.

\section{EXPERIMENTAL METHODS}

General Materials. $\mathrm{K}_{28} \mathrm{Li}_{5} \mathrm{H}_{7}\left[\mathrm{P}_{8} \mathrm{~W}_{48} \mathrm{O}_{184}\right] \cdot 92 \mathrm{H}_{2} \mathrm{O}$ and $\mathrm{Li}_{17}\left(\mathrm{NH}_{4}\right)_{21} \mathrm{H}_{2}\left[\mathrm{P}_{8} \mathrm{~W}_{48} \mathrm{O}_{184}\right] \cdot 85 \mathrm{H}_{2} \mathrm{O}$ were prepared according to the published syntheses with minor modifications for optimization. ${ }^{48,49}$ All other starting materials were commercially available and used without further purification.

Instrumentation and Techniques. Single-crystal XRD data sets were collected at $150 \mathrm{~K}$ on an Oxford Diffraction Gemini Ultra $S$ instrument equipped with a graphite monochromator and ATLAS CCD detector, or a Bruker Apex II Quasar instrument with CCD detector $\left(\lambda_{\mathrm{Mo} \mathrm{K} \alpha}=0.71073 \AA\right)$. Inductively coupled plasma optical emission spectroscopy (ICP-OES) was carried out on a TJA-IRISAdvantage spectrometer, with echelle optics and a CID detector used to observe in the $170-900 \mathrm{~nm}$ wavelength range. A minimum of 10 $\mathrm{mg}$ of each compound was submitted to the Institut für Festkörperforschung in Jülich for analysis. Samples were digested in a 1:1 mixture of $\mathrm{HNO}_{3}$ and $\mathrm{H}_{2} \mathrm{O}_{2}$. Where relevant, carbon, hydrogen, and nitrogen content were determined by the microanalysis services within the School of Chemistry, University of Glasgow, using an EA 1110 CHNS, CE-440 elemental analyzer. For Fourier transform infrared (FT-IR) spectroscopy, the materials were prepared as $\mathrm{KBr}$ pellets, and FT-IR spectra were collected in transmission mode using a JASCO FT/IR 4100 spectrometer. Wavenumbers $(\nu)$ are given in $\mathrm{cm}^{-1}$; intensities are denoted as wk $=$ weak, $\mathrm{sh}=$ sharp, $\mathrm{m}=$ medium, $\mathrm{br}=$ broad, $\mathrm{s}=$ strong. Thermogravimetric analysis (TGA) was performed on a TA Instruments Q500 thermogravimetric analyzer.

Synthesis of $K_{8} L_{17}\left[\mathrm{Mn}_{6.5}\left\{W_{0.5} \mathrm{O}_{0.5}\right\} \mathrm{P}_{8} W_{48} \mathrm{O}_{184}\right] \cdot 91 \mathrm{H}_{2} \mathrm{O}$ (1). To 20 $\mathrm{mL}$ of $2 \mathrm{~mol} \mathrm{~L}^{-1} \mathrm{LiCH}_{3} \mathrm{CO}_{2}$ buffer solution $(\mathrm{pH} 4.0)$ in a $50 \mathrm{~mL}$ round-bottomed flask was added $\mathrm{Mn}\left(\mathrm{ClO}_{4}\right)_{2} \cdot \mathrm{xH}_{2} \mathrm{O}(102 \mathrm{mg}, 0.40$ mmol), followed 5 min later by $\mathrm{K}_{28} \mathrm{Li}_{5} \mathrm{H}_{7}\left[\mathrm{P}_{8} \mathrm{~W}_{48} \mathrm{O}_{184}\right] \cdot 92 \mathrm{H}_{2} \mathrm{O}(100$ $\mathrm{mg}, 6.75 \mu \mathrm{mol}$ ). After a further $5 \mathrm{~min}$ of rapid stirring, the resulting pale yellow solution was then heated to $80^{\circ} \mathrm{C}$ overnight on a hot plate with a reflux condenser attached (approximately $20 \mathrm{~h}$ ) upon which it gained a more vibrant golden color. After cooling slowly back to room temperature while still on the hot plate and connected to the condenser, the solution was transferred to a $50 \mathrm{~mL}$ conical flask and covered, before being placed in the refrigerator $\left(4{ }^{\circ} \mathrm{C}\right)$ for crystallization. Large, rectangular yellow plate crystals formed overnight and were collected after 5 days. Yield: $19.8 \mathrm{mg}, 1.36$ $\mu$ mol, $20.1 \%$ based on $\left[\mathrm{P}_{8} \mathrm{~W}_{48} \mathrm{O}_{184}\right]^{40-}$. ICP-OES analysis for the hydrated material, $\mathrm{H}_{182} \mathrm{~K}_{8} \mathrm{Li}_{17} \mathrm{Mn}_{6.5} \mathrm{O}_{275.5} \mathrm{P}_{8} \mathrm{~W}_{48.5}, \mathrm{MW}=14543.82 \mathrm{~g}$ $\mathrm{mol}^{-1}$. Calculated values (found values in parentheses): $\mathrm{K} 2.14$ (2.18), Li 0.80 (0.79), Mn 2.45 (2.54), P 1.70 (1.70) W 61.3 (63.1). Characteristic FTIR bands: 1620 (s), 1133 (s, sh), 1086 (s, sh), 1022 (w), 933 (s), 798 (br), 698 (br). TGA water loss from 20 to $250{ }^{\circ} \mathrm{C}$, calculated (found): 11.3 (11.3) \%.

Synthesis of $\mathrm{Li}_{18} \mathrm{Mn}_{8}\left(\mathrm{NH}_{4}\right)_{6}\left[\mathrm{P}_{8} \mathrm{~W}_{48} \mathrm{O}_{184}\right] \cdot 113 \mathrm{H}_{2} \mathrm{O}$ (2). To a $20 \mathrm{~mL}$ buffer solution of $2 \mathrm{~mol} \mathrm{~L}^{-1} \mathrm{LiCH}_{3} \mathrm{CO}_{2}$ at $\mathrm{pH} 4.0$ in a $50 \mathrm{~mL}$ roundbottomed flask was first added $\mathrm{Mn}\left(\mathrm{ClO}_{4}\right)_{2} \cdot x \mathrm{H}_{2} \mathrm{O}(102 \mathrm{mg}, 0.40$ $\mathrm{mmol}$ ), followed 5 min later by $\mathrm{Li}_{17}\left(\mathrm{NH}_{4}\right)_{21} \mathrm{H}_{2}\left[\mathrm{P}_{8} \mathrm{~W}_{48} \mathrm{O}_{184}\right] \cdot 85 \mathrm{H}_{2} \mathrm{O}$ (93 $\mathrm{mg}, 6.75 \mu \mathrm{mol}$ ). After a further $5 \mathrm{~min}$ of rapid stirring, the white 
suspension was then heated to $90{ }^{\circ} \mathrm{C}$ on a hot plate with a reflux condenser attached, giving a lightly colored, clear, golden solution. After stirring at $90{ }^{\circ} \mathrm{C}$ overnight (approximately $20 \mathrm{~h}$ ), the reaction mixture was allowed to cool slowly back to room temperature while still on the hot plate and connected to the condenser, before being filtered into four narrow test tubes. The test tubes were plugged with cotton wool and placed in a container, which was roughly $10 \%$ filled with methanol, to facilitate crystal growth. Well-formed, pale yellow, hexagonal block crystals appeared in solution after 5 days. Yield: 22.0 $\mathrm{mg}, 1.49 \mu \mathrm{mol}, 22.1 \%$ based on $\left[\mathrm{P}_{8} \mathrm{~W}_{48} \mathrm{O}_{184}\right]^{40-}$. ICP-OES and CHN analysis for the hydrated material, $\mathrm{H}_{250} \mathrm{Li}_{18} \mathrm{Mn}_{8} \mathrm{~N}_{6} \mathrm{O}_{297} \mathrm{P}_{8} \mathrm{~W}_{48}, \mathrm{MW}=$ $14725.04 \mathrm{~g} \mathrm{~mol}^{-1}$. Calculated values (found values in parentheses): $\mathrm{Li}$ 0.86 (0.92), Mn 2.98 (2.93), N 0.57 (0.), P 1.68 (1.71), W 59.9 (62.9). Characteristic FTIR bands: 1620 (s), 1402 (s), 1134 (s, sh), 1084 (s, sh), $1022(\mathrm{w}), 932(\mathrm{~s}), 797(\mathrm{~m}), 673(\mathrm{br})$. TGA water loss from 20 to $250{ }^{\circ} \mathrm{C}$, calculated (found): 13.8 (13.8)\%.

Synthesis of $\mathrm{Li}_{22}\left(\mathrm{NH}_{4}\right)_{5} \mathrm{Ni}_{6}\left[\left\{\mathrm{~W}_{0.25} \mathrm{O}_{0.25}\right\} \mathrm{P}_{8} \mathrm{~W}_{48} \mathrm{O}_{184}\right] \cdot 90 \mathrm{H}_{2} \mathrm{O}$ (3). To 20 $\mathrm{mL}$ of $2 \mathrm{~mol} \mathrm{~L}^{-1} \mathrm{LiCH}_{3} \mathrm{CO}_{2}$ buffer solution at $\mathrm{pH} 4.0$ in a $50 \mathrm{~mL}$ round-bottomed flask was added $\mathrm{NiCl}_{2} \cdot 6 \mathrm{H}_{2} \mathrm{O}(88 \mathrm{mg}, 0.37 \mathrm{mmol})$, followed 5 min later by $\mathrm{Li}_{12}\left(\mathrm{NH}_{4}\right)_{21} \mathrm{H}_{7}\left[\mathrm{P}_{8} \mathrm{~W}_{48} \mathrm{O}_{184}\right] \cdot 85 \mathrm{H}_{2} \mathrm{O}(102 \mathrm{mg}$, $6.75 \mu \mathrm{mol}$ ). After a further $5 \mathrm{~min}$ of rapid stirring, the resulting applegreen solution was heated to $90^{\circ} \mathrm{C}$ for $25 \mathrm{~h}$ on a hot plate with a reflux condenser attached. After cooling slowly back to room temperature while still on the hot plate and connected to the condenser, the solution was syringe-filtered and divided between four narrow test tubes, which were plugged with cotton wool. Each test tube was place in the same large container, which was roughly $10 \%$ filled with acetone. Pale green plate crystals were observed in the test tubes after 5 days and collected 1 week later. Yield: $11.5 \mathrm{mg}, 0.80 \mu \mathrm{mol}, 11.9 \%$ based on $\left[\mathrm{P}_{8} \mathrm{~W}_{48} \mathrm{O}_{184}\right]^{40-}$. ICP-OES and $\mathrm{CHN}$ analysis for the hydrated material, $\mathrm{H}_{200} \mathrm{Li}_{22} \mathrm{~N}_{5} \mathrm{Ni}_{6} \mathrm{O}_{274.25} \mathrm{P}_{8} \mathrm{~W}_{48.25}, \quad \mathrm{MW}=14283.57 \mathrm{~g} \mathrm{~mol}^{-1}$. Calculated values (found values in parentheses): $\mathrm{Li} 1.08$ (1.12), N 0.49 (0.49), Ni 2.43 (2.45), P 1.73 (1.82), W 62.1 (59.4). Characteristic FTIR bands: 1635 (br), 1399 (sh), 1132 (s, sh), 1083 (s, sh), 1019 (w), 934 (s, br), $704(\mathrm{~m}), 663$ (br). TGA water loss from 20 to 250 ${ }^{\circ} \mathrm{C}$, calculated (found): 11.4 (11.4)\%.

\section{RESULTS AND DISCUSSION}

New Frameworks Based on $\left\{\mathrm{P}_{8} \mathbf{W}_{48}\right\}$. By utilizing the minimal building block library of $\left\{\mathrm{P}_{8} \mathrm{~W}_{48}\right\}$ nodes and $\mathrm{TM}$ linkers, three new coordinatively linked inorganic frameworks have been synthesized. Each compound has been prepared in a modular fashion, with the intrinsically porous POM building block formed prior to the assembly of the frameworks. The same general synthetic system was employed in each case, based on a lithium acetate buffer solution at $\mathrm{pH} 4.0$, heated to just below boiling and stirred overnight. These compounds further expand the growing family of TM-linked $\left\{\mathrm{P}_{8} \mathrm{~W}_{48}\right\}$ structures.

$\mathrm{K}_{8} \mathrm{Li}_{17}\left[\mathrm{Mn}_{6.5}\left\{\mathrm{~W}_{0.5} \mathrm{O}_{0.5}\right\} \mathrm{P}_{8} \mathrm{~W}_{48} \mathrm{O}_{184}\right] \cdot 91 \mathrm{H}_{2} \mathrm{O}$ (compound $\mathbf{1}$, Figure 2) was crystallized from lithium acetate buffer solution following the reaction of $\mathrm{Mn}\left(\mathrm{ClO}_{4}\right)_{2}$ with $\mathrm{K}_{28} \mathrm{Li}_{5} \mathrm{H}_{7}\left[\mathrm{P}_{8} \mathrm{~W}_{48} \mathrm{O}_{184}\right] \cdot 92 \mathrm{H}_{2} \mathrm{O}$. Each $\left\{\mathrm{P}_{8} \mathrm{~W}_{48}\right\}$ ring in the structure is coordinated to $8.5 \mathrm{Mn}^{\mathrm{II}}$ centers $\left(4 \mathrm{Mn}^{\mathrm{II}}\right.$ centers are shared between adjacent rings, hence there are only 6.5 $\mathrm{Mn}^{\mathrm{II}}$ atoms in the formula). Two $\mathrm{Mn}$ atoms are positioned in the internal cavity of the ring, occupying hinge sites on opposite sides of the cluster, in octahedral coordination environments of two POM terminal oxygen ligands $\left(\mathrm{W}=\mathrm{O}_{\mathrm{T}}\right)$, and four water molecules. Two Mn atoms are coordinated on the outside of the remaining two hinge regions, also through two $\mathrm{W}=\mathrm{O}_{\mathrm{T}}$ sites. These $\mathrm{Mn}$ atoms, and another two $\mathrm{Mn}$ atoms situated on the outside of the ring (coordinated to only one $\mathrm{W}=\mathrm{O}_{\mathrm{T}}$ ), are shared between adjacent $\left\{\mathrm{P}_{8} \mathrm{~W}_{48}\right\}$ rings. $\mathrm{Mn}$ atoms occupy a further two equivalent sites on the external surface of the ring in a disordered fashion across roughly one in every four clusters in

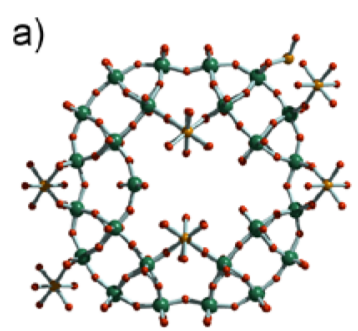

b)

c)
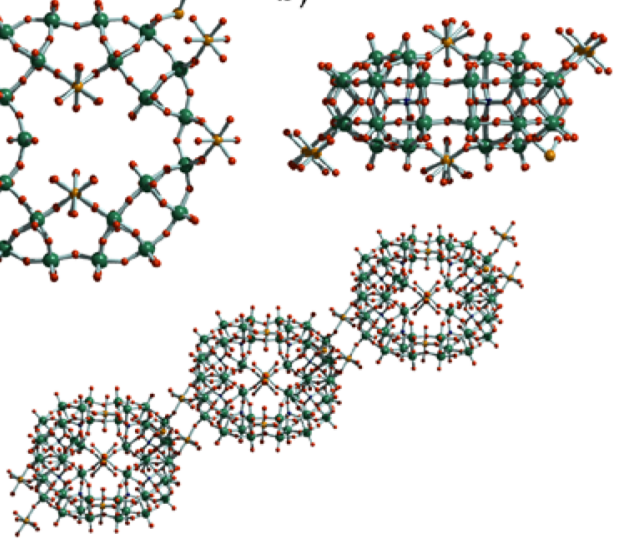

Figure 2. Ball-and-stick representation of the $\left\{\mathrm{P}_{8} \mathrm{~W}_{48}\right\} \mathrm{SBU}$ in compound 1 from (a) top-down and (b) side-on. (c) "Stepped chain" connectivity of POMzite-1(Mn) in one dimension. Dark green spheres, $\mathrm{W}$; red spheres, $\mathrm{O}$; orange spheres, $\mathrm{Mn}$; dark blue spheres, $\mathrm{P}$.

the crystal. As has been observed previously, ${ }^{50}$ the four-fold symmetry of the parent cluster is distorted, and an additional 49th tungsten center is accommodated within the hinge region of the $\left\{\mathrm{P}_{8} \mathrm{~W}_{48}\right\}$ rings, occupationally disordered across half of the clusters throughout the crystal.

The four shared $\mathrm{Mn}$ atoms which are coordinated to the outer surface of $\left\{\mathrm{P}_{8} \mathrm{~W}_{48}\right\}$ connect the rings into a onedimensional chain. Each ring is oriented in the same manner, but coordinated rings are displaced both horizontally and vertically, resulting in a diagonal, stepped, polymeric structure. In the crystal packing, potassium and lithium cations, as well as solvent water molecules, form a supramolecular bridge between chains in a disorder fashion. Similarly, these alkali metal cations and water molecules are also situated inside the $\left\{\mathrm{P}_{8} \mathrm{~W}_{48}\right\}$ ring cavities, and could potentially be exchanged by solid-state cation sorption experiments, as observed for similar structures. $^{51}$

In a c cordance with compound 1 , $\mathrm{Li}_{18} \mathrm{Mn}_{8}\left(\mathrm{NH}_{4}\right)_{6}\left[\mathrm{P}_{8} \mathrm{~W}_{48} \mathrm{O}_{184}\right] \cdot 113 \mathrm{H}_{2} \mathrm{O}$ (compound 2, Figure 3)

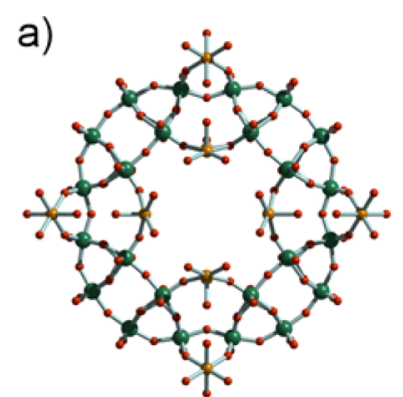

b)

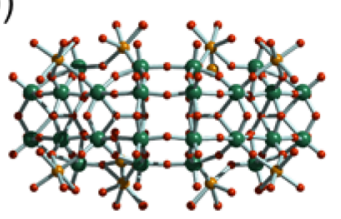

c)

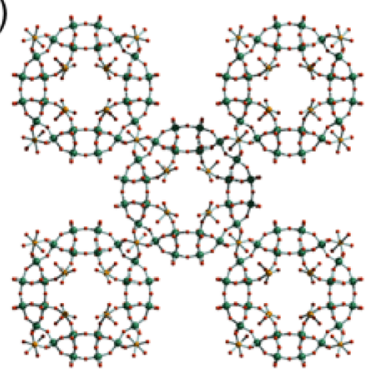

d)

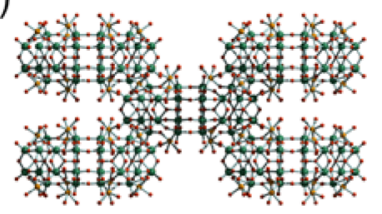

Figure 3. Ball-and-stick representation of the $\left\{\mathrm{P}_{8} \mathrm{~W}_{48}\right\}$ SBU in compound 2 from (a) top-down and (b) side-on. Connectivity of POMzite-13(Mn) in three dimensions from (c) top-down and (d) side-on. Dark green spheres, W; red spheres, O; orange spheres, Mn; dark blue spheres, P. 
was formed in a lithium acetate buffered reaction mixture of $\mathrm{Mn}\left(\mathrm{ClO}_{4}\right)_{2}$ and $\left\{\mathrm{P}_{8} \mathrm{~W}_{48}\right\}$. However, in contrast to the preparation of compound $\mathbf{1}$, the synthesis of compound $\mathbf{2}$ utilized the $\mathrm{Li}_{17}\left(\mathrm{NH}_{4}\right)_{21} \mathrm{H}_{2}\left[\mathrm{P}_{8} \mathrm{~W}_{48} \mathrm{O}_{184}\right] \cdot 85 \mathrm{H}_{2} \mathrm{O}$ starting material instead of $\mathrm{K}_{28} \mathrm{Li}_{5} \mathrm{H}_{7}\left[\mathrm{P}_{8} \mathrm{~W}_{48} \mathrm{O}_{184}\right] \cdot 92 \mathrm{H}_{2} \mathrm{O}$. The influence of specific alkali metal cations on the assembly of $\left\{\mathrm{P}_{8} \mathrm{~W}_{48}\right\}$-based frameworks has previously been discussed; however, until the recent preparation of a potassium-deficient salt of $\left\{\mathrm{P}_{8} \mathrm{~W}_{48}\right\},{ }^{49}$ this effect could not be directly investigated.

Compound 2 has eight $\mathrm{Mn}^{\mathrm{II}}$ centers situated on the outside of the $\left\{\mathrm{P}_{8} \mathrm{~W}_{48}\right\}$ hinge regions, each coordinated to two POM $\mathrm{W}=\mathrm{O}_{\mathrm{T}}$ sites (these are all shared with adjacent rings, and so constitute only four $\mathrm{Mn}$ atoms in the formula of the compound). Incidentally, this position is also occupied in compound 1, but only at two hinge sites instead of eight. The remaining coordinated $\mathrm{Mn}^{\mathrm{II}}$ centers in compound $\mathbf{2}$ reside in the center of the $\left\{\mathrm{P}_{8} \mathrm{~W}_{48}\right\}$ cavity, disordered across the inside of each hinge site. Again, this is the same site which is occupied in compound 1. Additional Mn content, identified by ICP-OES but not observed crystallographically, is assumed not to be coordinated to $\left\{\mathrm{P}_{8} \mathrm{~W}_{48}\right\}$, but to reside in the pores of the framework structure as charge-balancing, and potentially exchangeable, $\left[\mathrm{Mn}\left(\mathrm{H}_{2} \mathrm{O}\right)_{6}\right]^{2+}$ countercation. Each ring in compound 2 retains the approximate $D_{4 h}$ symmetry of the parent $\left\{\mathrm{P}_{8} \mathrm{~W}_{48}\right\}$ structure, with no additional tungsten content in the hinge positions. $\left\{(\mathrm{W}-\mathrm{O})_{2}-\mathrm{Mn}-(\mathrm{O}-\mathrm{W})_{2}\right\}$ bridges connect each ring to eight surrounding clusters. All rings are oriented in a uniform manner throughout the framework, creating a three-dimensional framework with layers stacked directly on top of each other in an $A B A B$ fashion. This arrangement of $\left\{\mathrm{P}_{8} \mathrm{~W}_{48}\right\}$ into parallel columns creates cylindrical channels of roughly $1 \mathrm{~nm}$ diameter, in which reside a mixture of the crystallographically unaccounted-for [Mn$\left.\left(\mathrm{H}_{2} \mathrm{O}\right)_{6}\right]^{2+}$ cations, $\mathrm{NH}_{4}^{+}$cations, $\mathrm{Li}^{+}$cations, and solvent water molecules.

By recognizing the role played by $\mathrm{NH}_{4}^{+}$cations in the synthesis of compound 2, the potassium-free starting material, $\mathrm{Li}_{17}\left(\mathrm{NH}_{4}\right)_{21} \mathrm{H}_{2}\left[\mathrm{P}_{8} \mathrm{~W}_{48} \mathrm{O}_{184}\right] \cdot 85 \mathrm{H}_{2} \mathrm{O}$, was investigated for its effect on the synthesis of further $\left\{\mathrm{P}_{8} \mathrm{~W}_{48}\right\}$-based compounds. Similarly, the recent publication of the first Ni-linked $\left\{\mathrm{P}_{8} \mathrm{~W}_{48}\right\}$ framework indicated that $\mathrm{Ni}$ could be a suitable $\mathrm{TM}$ to link $\left\{\mathrm{P}_{8} \mathrm{~W}_{48}\right\}$ clusters and add further new compounds based on this system. ${ }^{46}$ Consequently, $\mathrm{Li}_{22}\left(\mathrm{NH}_{4}\right)_{5} \mathrm{Ni}_{6}\left[\left\{\mathrm{~W}_{0.25} \mathrm{O}_{0.25}\right\}\right.$ $\left.\mathrm{P}_{8} \mathrm{~W}_{48} \mathrm{O}_{184}\right] \cdot 90 \mathrm{H}_{2} \mathrm{O}$ (compound 3, Figure 4), an Ni-linked, potassium-free $\left\{\mathrm{P}_{8} \mathrm{~W}_{48}\right\}$-based compound was formed under typical reaction conditions. In this compound, a total of six $\mathrm{Ni}^{\mathrm{II}}$ atoms have been identified by ICP-OES; however, only $4.2 \mathrm{Ni}$ centers have been located crystallographically. As in compound 1, the inner hinge sites are filled in two positions, on opposite sides of the ring. The remaining $\mathrm{Ni}^{\mathrm{II}}$ atoms are located on the outer surface of the ring, with significant positional disorder preventing crystallographic resolution of their complete coordination environments. Again similarly to compound 1, the four-fold symmetry of the parent cluster is distorted, and an additional 49th tungsten center is accommodated within the hinge region of the rings. In compound 3, this supplementary position is occupationally disordered over a quarter of the clusters throughout the crystal.

Compound 3 has a planar one-dimensional chain-type structure, and as with the two previously described compounds, each $\left\{\mathrm{P}_{8} \mathrm{~W}_{48}\right\}$ cluster is oriented uniformly throughout the crystal. However, in contrast to the chains of compound 1, each of the connected rings resides in the same plane. Vacancies in

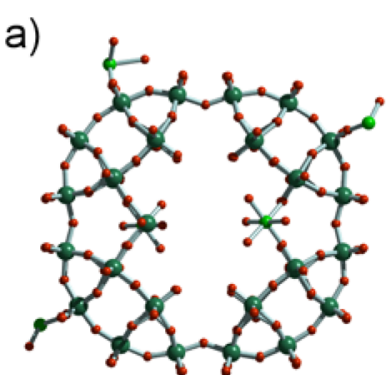

b)

C)

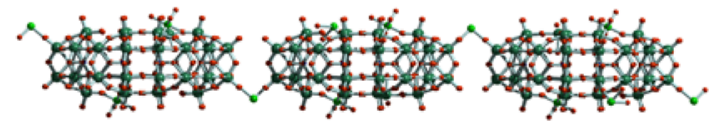

Figure 4. Ball-and-stick representation of the $\left\{\mathrm{P}_{8} \mathrm{~W}_{48}\right\} \quad \mathrm{SBU}$ in compound 3 from (a) top-down and (b) side-on. (c) "Planar chain" connectivity of POMzite-14(Ni) in one dimension. Dark green spheres, W; red spheres, O; light green spheres, $\mathrm{Mn}$; dark blue spheres, P.

the structure of compound 3 are occupied by a combination of $\mathrm{NH}_{4}^{+}$and $\mathrm{Li}^{+}$cations, solvent water molecules, and the remaining $\left[\mathrm{Ni}\left(\mathrm{H}_{2} \mathrm{O}\right)_{6}\right]^{2+}$ cations which are not coordinated directly to the ring via dative bonds.

During the course of this work, a number of additional frameworks based on $\left\{\mathrm{P}_{8} \mathrm{~W}_{48}\right\}$ and TMs have been identified. However, many of the compounds currently suffer from a lack of reproducibility and are yet to be fully characterized. Among the strategies which have shown promise so far include the introduction of secondary cations to the reaction mixture, the results of which approach will be reported in due course. However, the rapid expansion of this class of materials has highlighted the need for a greater understanding of the nature of TM coordination to $\left\{\mathrm{P}_{8} \mathrm{~W}_{48}\right\}$, and its subsequent extension into multidimensional frameworks. Further, the establishment of a classification system to cover all one-, two-, and threedimensional $\left\{\mathrm{P}_{8} \mathrm{~W}_{48}\right\}$-based structures is needed to facilitate both the identification and discussion of new compounds.

Coordination of Transition Metals to $\left\{\mathrm{P}_{8} \mathrm{~W}_{48}\right\}$. Although the nanometer-sized cavity of $\left\{\mathrm{P}_{8} \mathrm{~W}_{48}\right\}$ makes it an ideal building block for the modular construction of porous frameworks, its TM-mediated extension into multidimensional architectures has so far been plagued by unpredictability. This is primarily because there are several sites around the $\left\{\mathrm{P}_{8} \mathrm{~W}_{48}\right\}$ ring to which TMs may coordinate, causing rings which are connected through one or more common TM atoms to adopt a variety of different positions and orientations in relation to each other. Crucially, the specific nanoscale arrangement of neighboring rings determines the long-range organization of $\left\{\mathrm{P}_{8} \mathrm{~W}_{48}\right\}$ on the mesoscale, into coordinatively linked, one-, two-, or three-dimensional structures. Such topological diversity arises despite the same minimal library of building blocks being employed in each case. In order to control the extension of the effectively 0-D $\left\{\mathrm{P}_{8} \mathrm{~W}_{48}\right\}$ SBU into higher-dimensional structures, it is therefore crucial to gain a clearer insight into TM coordination to $\left\{\mathrm{P}_{8} \mathrm{~W}_{48}\right\}$ by fully mapping the binding sites of the heteropolyanion, and using the wealth of information available from the TM-linked $\left\{\mathrm{P}_{8} \mathrm{~W}_{48}\right\}$ structures which are currently known (a complete list of the compounds considered in this study is given in the Supporting Information).

In general, POMs act as nucleophilic O-donor ligands for the coordination of first-row TMs. More specifically, the $\left\{\mathrm{P}_{8} \mathrm{~W}_{48}\right\}$ 
ring features a total of 64 reactive, coordinatively unsaturated terminal oxygen $\left(\mathrm{W}=\mathrm{O}_{\mathrm{T}}\right)$ sites to which $3 \mathrm{~d}$ TMs may bind. Despite this apparent complexity, however, in its idealized $D_{4 h}$ configuration there are only four inequivalent groups of $\mathrm{W}=$ $\mathrm{O}_{\mathrm{T}}$, each made up of 16 equiv sites around the ring, and labeled either A, B, C, or D according to their environment (Figure 5).

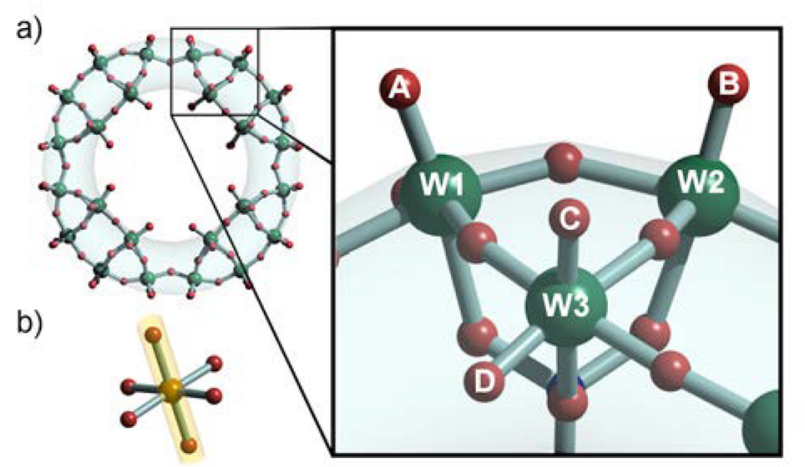

Figure 5. (a) $\left\{\mathrm{P}_{8} \mathrm{~W}_{48}\right\}$ ring-shaped $\mathrm{SBU}$ node, with close-up of the smallest repeating $\left[\mathrm{P}_{0.5} \mathrm{~W}_{3} \mathrm{O}_{11.5}\right]^{2.5-}$ subunit, highlighting the three inequivalent $\mathrm{W}$ atoms and four inequivalent $\mathrm{W}=\mathrm{O}_{\mathrm{T}}$ (labeled $\mathrm{A}, \mathrm{B}, \mathrm{C}$, and $\mathrm{D})$. (b) Octahedral $\left\{\mathrm{TMO}_{6}\right\}$ linker $(\mathrm{TM}=\mathrm{Mn}, \mathrm{Co}, \mathrm{Ni})$ which can be used to connect adjacent $\left\{\mathrm{P}_{8} \mathrm{~W}_{48}\right\}$ SBUs.

Although TM binding is a prerequisite for the extension of $\left\{\mathrm{P}_{8} \mathrm{~W}_{48}\right\}$ into a coordination polymer, it does not always result in ring connectivity. Pendant metal coordination, in cases where TM cations are bound to only one $\left\{\mathrm{P}_{8} \mathrm{~W}_{48}\right\}$ SBU, has been observed at each of the four binding sites around the ring (Figure 6). In accordance with the labeling system for these sites, the binding modes of the four possible monodentate pendant positions can in turn be labeled A, B, C, or D according to the identity of the coordinated $\mathrm{W}=\mathrm{O}_{\mathrm{T}}$.

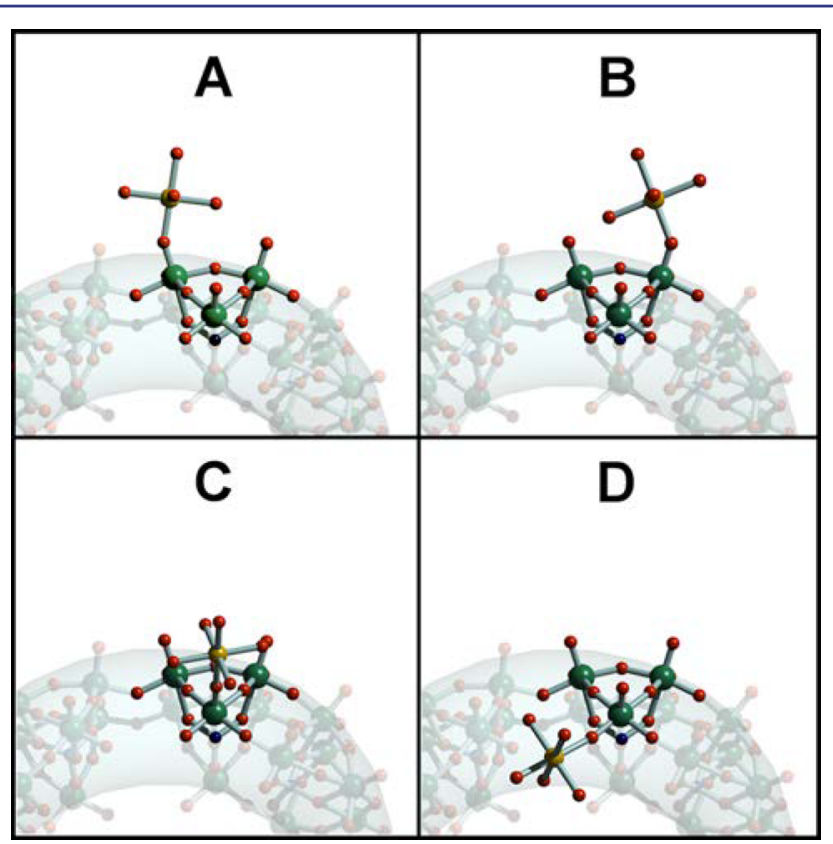

Figure 6. Four types of monodentate pendant coordination modes, labeled A, B, C, and D according to the identity of the coordinated terminal oxygen.
In addition to the simple monodentate nonbridging modes of TM coordination to $\left\{\mathrm{P}_{8} \mathrm{~W}_{48}\right\}$, the two components may also be combined in bidentate fashion (Figure 7). There are 10

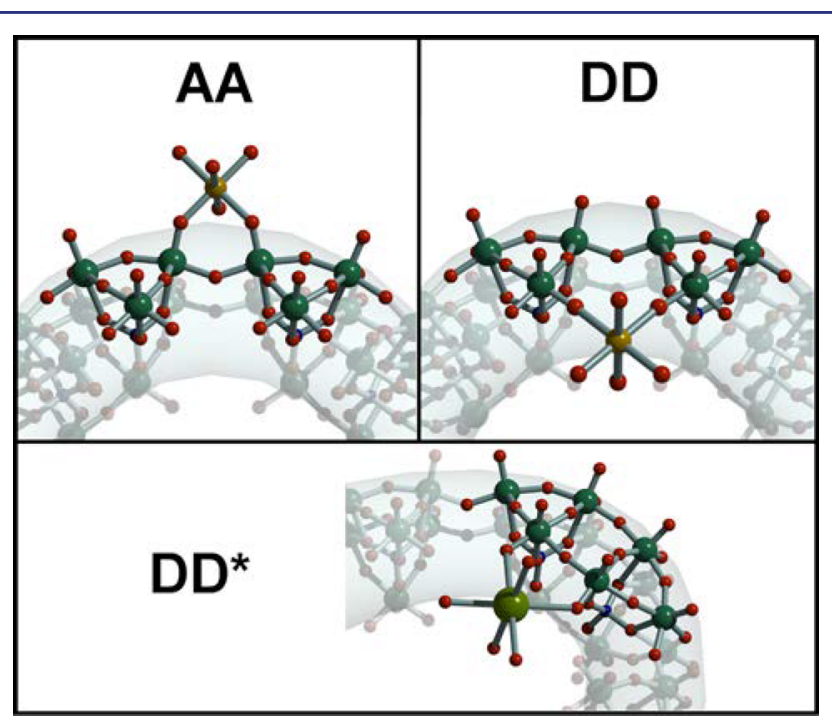

Figure 7. Three observed modes of bidentate pendant coordination, labeled AA, DD, and DD* according to the identity of the coordinated terminal oxygens. Note that $\mathrm{DD}^{*}$ coordination has only been observed for f-block transition metals.

potential bidentate modes of coordination based on the binary combination of recognized $\mathrm{W}=\mathrm{O}_{\mathrm{T}}$ sites; however, only $\mathrm{AA}$ and $\mathrm{DD}$ combinations have been observed for the first-row TMs. In addition to these sites at the "hinge" region of $\left\{\mathrm{P}_{8} \mathrm{~W}_{48}\right\}$, a third mode is possible when $\left\{\mathrm{P}_{8} \mathrm{~W}_{48}\right\}$ is reacted with f-block metals. ${ }^{47}$ Labeled DD*, these binding sites are on the inner face of $\left\{\mathrm{P}_{8} \mathrm{~W}_{48}\right\}$, and are seemingly favored by bulkier cations, due to the typically larger spacing between the $\mathrm{O}$ termini in comparison with the DD coordination mode. Moreover, the three observed bidentate pendant modes of $\mathrm{TM}$ binding to $\left\{\mathrm{P}_{8} \mathrm{~W}_{48}\right\}$ suggest that bidentate nonbridging coordination is forbidden for two different $\mathrm{W}=\mathrm{O}_{\mathrm{T}}$ sites of the same $\left\{\mathrm{P}_{8} \mathrm{~W}_{48}\right\}$ ring.

Transition metals which are bound to $\left\{\mathrm{P}_{8} \mathrm{~W}_{48}\right\}$ in pendant modes undoubtedly have a significant influence on the general properties of the compound. Pendant TMs typically have at least four coordination sites occupied by aqua ligands, which may be exchangeable in nonaqueous solvents. In MOF chemistry, open metal sites are commonly attributed with enhancing catalytic activity, improving uptake, and increasing the specificity of interactions. We have also demonstrated that pendant sites in $\left\{\mathrm{P}_{8} \mathrm{~W}_{48}\right\}$-based structures may be activated to form linkers, and in turn entirely new frameworks, which are only accessible through an intermediary, preorganized structure with nonbridging TMs. ${ }^{35}$ Although pendant sites must not be ignored in POMzite chemistry, the extension of $\left\{\mathrm{P}_{8} \mathrm{~W}_{48}\right\}$ into multidimensional structures requires the coordination of TM centers which are common to two or more $\left\{\mathrm{P}_{8} \mathrm{~W}_{48}\right\}$ SBUs.

As with the small number of observed bidentate pendant coordination modes, there are many potential combinations of pendant-type coordination modes which are not, or are only rarely, observed as linkers. Of the common linker modes, three may be considered as homotopic i.e., bridging between the same sites of two $\left\{\mathrm{P}_{8} \mathrm{~W}_{48}\right\}$ SBUs (Figure 8). These are labeled $\mathrm{AAA}^{\prime} \mathrm{A}^{\prime}, \mathrm{BB}^{\prime}$, and $\mathrm{CC}^{\prime}$, where the prime indicates the 


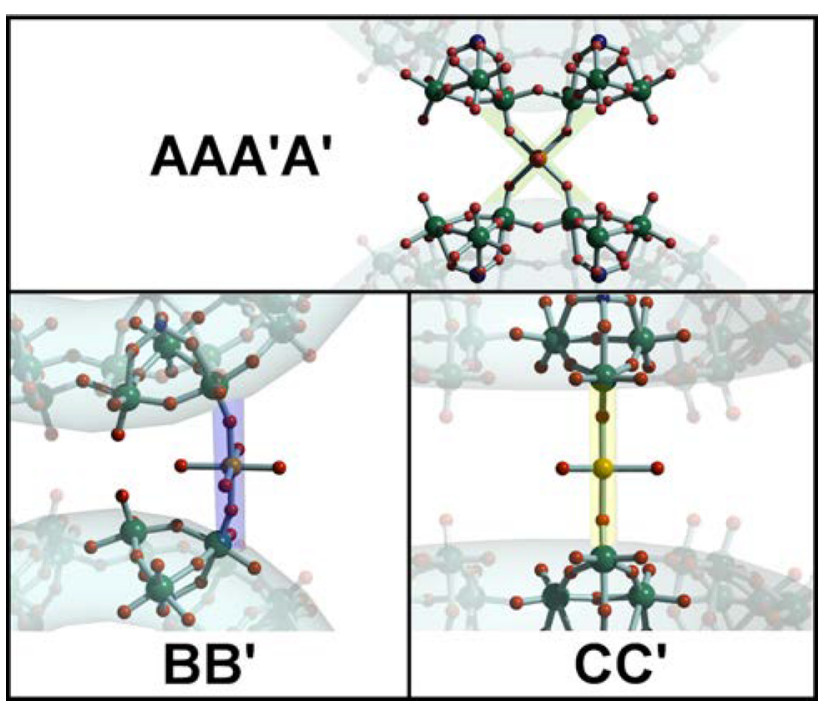

Figure 8. Three main homotopic linker coordination modes observed in POMzites: A-type linkage, green; B-type linkage, blue; C-type linkage, yellow.

coordination of a site from a second ring. Further, there are four common heterotopic linker modes which bridge neighboring rings via two different binding sites (Figure 9).

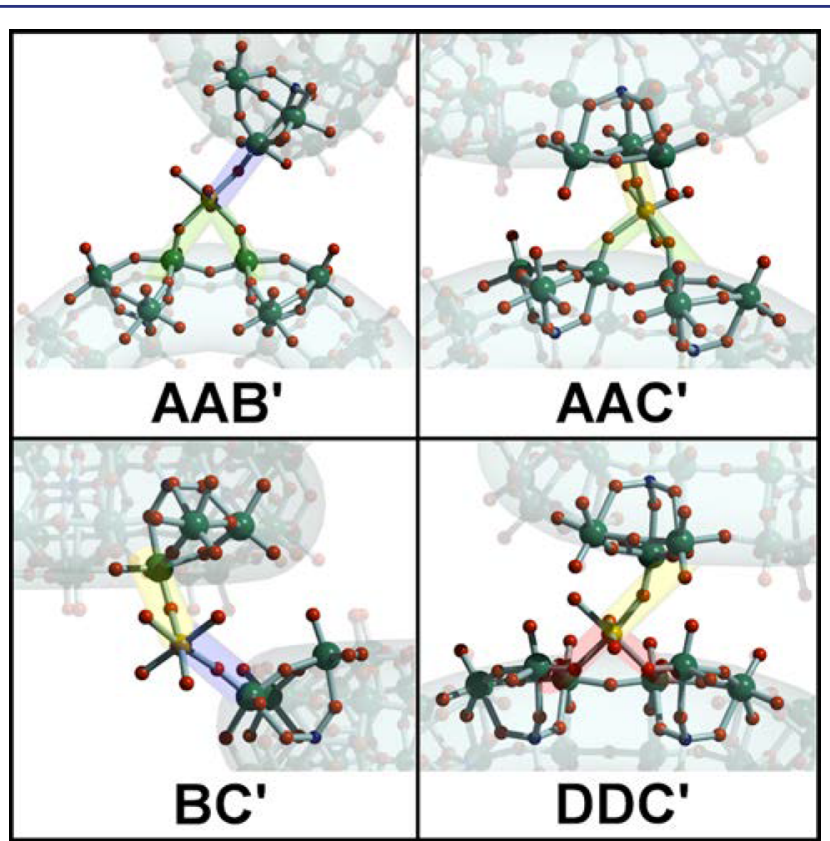

Figure 9. Four main heterotopic linker coordination modes observed in POMzites: A-type linkage, green; B-type linkage, blue; C-type linkage, yellow; D-type linkage, red.

Following the same convention as for the labeling of homotopic linkers, the heterotopic linkers are designated as $\mathrm{AAB}^{\prime}, \mathrm{AAC}^{\prime}$, $\mathrm{BC}^{\prime}$, and $\mathrm{DDC}^{\prime}$. As the seven common linker modes are crucial in determining the positional and orientational relationships between neighboring rings, they play a crucial structuredirecting role in the extension of $\left\{\mathrm{P}_{8} \mathrm{~W}_{48}\right\}$ into coordinatively linked frameworks, and are responsible for the structural diversity seen for the POMzite family of materials.

POMzite Topology and Taxonomy. Four main structural types of POMzite have been observed so far, namely chain, column, herringbone, and cube (Figure 10). The simplest structural type is the chain arrangement, seen for both

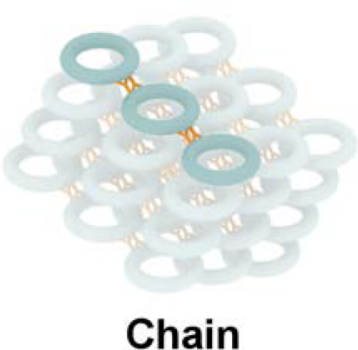

Chain

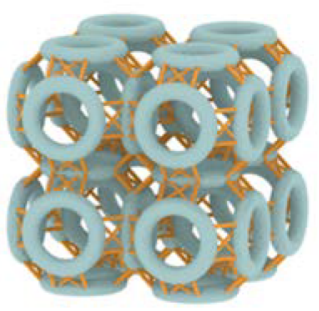

Cube

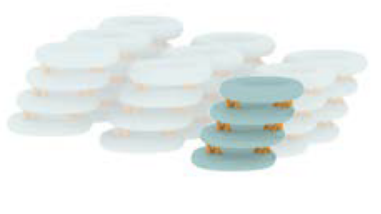

Column

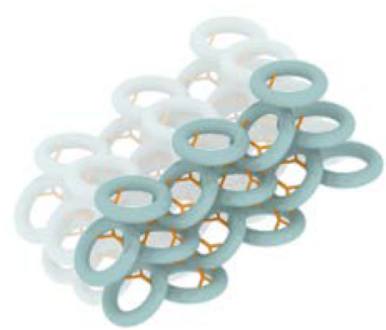

Herringbone
Figure 10. Representative models for the four structural types of known POMzites: chain, column, cube, and herringbone.

compounds 1 and 3 , in which $\left\{\mathrm{P}_{8} \mathrm{~W}_{48}\right\}$ rings are linked edgeto-edge in only one dimension. Each ring in the chain structure is orientated in a uniform fashion, and 2-coordinated, i.e., linked to two other rings. Similarly, each ring in the column structure has the same orientation, but the rings are connected in a faceto-face manner. The coordination number is also 2 if the rings are connected in only one dimension; however, column structures may also be linked into two or three dimensions by edge-to-edge connectivity. For two-dimensional structures, which may be considered as rows of columns, the coordination number is typically 6 , while for three-dimensional structures rings are 8-connected and reside in a columnar matrix. In both the herringbone and cube structures, there are two different ways in which the rings are orientated. In the two-dimensional herringbone structure, rings are related by an approximate $45^{\circ}$ rotation, with edge-to-face connectivity. Herringbone structures are typically 4-coordinated, but may also be linked edge-to-edge to become three-dimensional with higher coordination numbers. Finally, the cube architecture is a three-dimensional construct of 8-coordinated rings in a "stacked-box" arrangement, in which each ring is related by a $90^{\circ}$ rotation. It seems highly likely that further structure types will be identified in future. In particular, a sheet structure based on the chain arrangement with additional edge-to-edge connectivity in the second dimension is easy to visualize.

One of the major benefits of disentangling the complex connectivity of $\left\{\mathrm{P}_{8} \mathrm{~W}_{48}\right\}$ rings in POMzite structures by defining a limited number of linker modes, is that it allows simplified representations of the structures to be presented. This gives the reader a much greater insight into the threedimensional arrangements of $\left\{\mathrm{P}_{8} \mathrm{~W}_{48}\right\}$-based compounds than with conventional ball-and-stick models, and enables facile comparisons between POMzites to be made. In total, 14 unique POMzite architectures have been observed so far, and are numbered chronologically according to their date of publication 
Table 1. Chronological Numbering System for All Established POMzite Architectures, Their Structure Types, Pendant and Linker Modes, and Simplified Three-Dimensional Models of Each Structure ${ }^{a}$

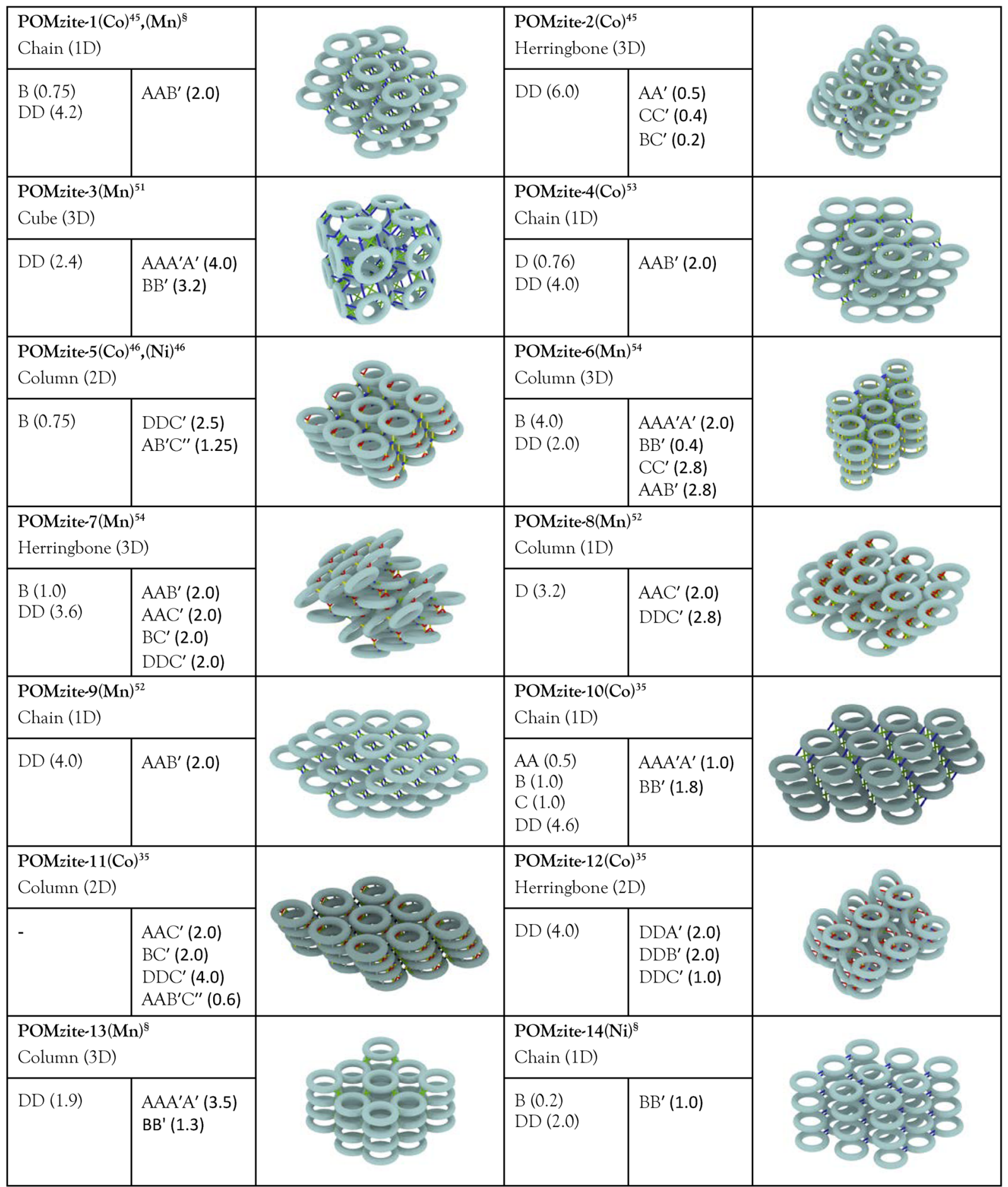

${ }^{a}$ For each POMzite the left-hand column details the pendant modes present and the right-hand column the linker modes (as described in the main text). The figures in parentheses are the TM occupancies of such sites per $\left\{\mathrm{P}_{8} \mathrm{~W}_{48}\right\}$ ring. For detailed composition of each POMzite architecture see Table S1. ${ }^{\S}$ This work.

(Table 1). If multiple compounds were presented in a single publication, the order of numbering within the article has been retained in the current system. Additionally, if more than one compound has been identified with any given structure, it is the publication date of the first compound to be presented which determines its numbering here. For example, the first multidimensional $\left\{\mathrm{P}_{8} \mathrm{~W}_{48}\right\}$ compound to be presented was the Co-linked structure, $\mathrm{K}_{15} \mathrm{Li}_{5}\left[\mathrm{Co}_{10}\left(\mathrm{H}_{2} \mathrm{O}\right)_{34}\left(\mathrm{P}_{8} \mathrm{~W}_{48} \mathrm{O}_{184}\right)\right]$. $54 \mathrm{H}_{2} \mathrm{O}$, labeled "compound 1" in a communication published in 2009 which presented two new compounds. ${ }^{45}$ Therefore, this compound may be labeled "POMzite-1(Co)" to indicate that this was the first POMzite discovered, and that it incorporated Co linkers. Compound 1, presented herein, is a Mn-linked analogue of POMzite-1(Co), appropriately termed 
"POMzite-1(Mn)". Isostructural POMzites have the same TM substitution patterns and connectivity, although they may differ in the actual occupancy of each TM coordination site. Indeed, we have observed small variations in heterometal content between crystals from different batches of a number of POM framework materials, although the batches are still considered to be of the same compound. In the future, reports of new POMzites should indicate the range of TM incorporation with which a material can be prepared. As the chemical formulas of POMzites are typically complex, and often quite similar, this universal system of nomenclature should simplify discussions concerning all POMzites.

By inspection of Table 1, it is apparent that a distinction has been made between several structures with similar substitution patterns and linker modes. In particular, POMzite-1, POMzite4, and POMzite-9 all have chain structures with $\mathrm{AAB}^{\prime}$ connectivity. In POMzite-1, the presence of an external TM coordinated in the $\mathrm{B}$ position sets it apart from the two other compounds for two reasons: (1) pendant functionality is important to the general properties of the framework and can be activated by single crystal to single crystal transformations, and (2) the steric effect of a TM positioned externally causes spatial displacement of adjacent chains in the solid state. The difference between POMzite- 4 and POMzite- 9 is much subtler. As the $\mathrm{AAB}^{\prime}$ linkers present in both compounds are heterotopic, they also have direction; i.e., they connect two inequivalent termini. In POMzite-4 and POMzite-9, the same positions are occupied in both compounds, but the direction of the $\mathrm{AAB}^{\prime}$ linkers is reversed. Notably, the authors of the latter publication did not refer to the prior-published compound when presenting POMzite- $9(\mathrm{Mn})$, despite its close similarity to POMzite-4(Co). ${ }^{52}$ Both the binding site analysis carried out here, and the structural model representations which this allowed, make compound comparisons much simpler. The differences between the three compounds discussed here can be much better understood using this system.

\section{CONCLUSIONS}

Three new compounds based on a minimal building block library of the cyclic polyoxometalate $\left\{\mathrm{P}_{8} \mathrm{~W}_{48}\right\}$ and transition metal cations have been prepared. Each material consists of a purely inorganic metal oxide scaffold, with intrinsic porosity resulting from the use of a crown-type building block. Despite the apparent limitations of employing only two main structural components, this study expands the number of frameworks based on this system to 14. Furthermore, a comprehensive $\left\{\mathrm{P}_{8} \mathrm{~W}_{48}\right\}$ binding site analysis of the literature has been performed to gain a greater understanding of how the various structure-types are accessed. As a result, a previously disparate group of compounds has been united and proposed to be named "POMzites".

POMzite materials have tremendous potential to bridge the gap in porous framework materials between MOF tunability and zeolite functionality. Previously, the structural complexity of these materials, and a lack of understanding regarding the connectivity within them, has held back their development. Due to their light nature, MOFs hold a clear technological advantage over POM framework materials for such applications as gas storage. However, in other applications POMzites may be a more effective alternative. The most obvious advantage is in catalysis, where the benefit of POMs is already realized by the dispersion of these clusters throughout MOF architectures. POMzites are self-supported porous materials with POM functionality inherent in their structure. In the future, the use of organic SDAs, a well-known strategy in zeolite synthesis, ${ }^{55}$ will be employed to access novel POMzite archetypes. The potential for further expanding this library is great, with possibilities to introduce other TMs and employ other SDAs representing just a couple of examples of how this might be achieved. It is highly likely that many more structures will arise from this fruitful chemical system through careful control of reaction conditions. Work is currently underway in our research group to fully utilize the pore space within these materials to exploit their unique pore environments.

\section{ASSOCIATED CONTENT}

\section{S Supporting Information}

The Supporting Information is available free of charge on the ACS Publications website at DOI: 10.1021/jacs.7b01807.

Tables S1-S6, giving details about the POM architectures for the taxonomy, structures, and X-ray data (PDF) $\mathrm{X}$-ray crystallographic data for $\mathbf{1}$ (CIF)

$\mathrm{X}$-ray crystallographic data for $\mathbf{2}$ (CIF)

$\mathrm{X}$-ray crystallographic data for 3 (CIF)

\section{AUTHOR INFORMATION}

\section{Corresponding Author}

*lee.cronin@glasgow.ac.uk

ORCID $\odot$

Leroy Cronin: 0000-0001-8035-5757

\section{Present Address}

${ }^{\ddagger}$ Y.-F.S.: State Key Laboratory of Chemical Resource Engineering, Beijing University of Chemical Technology, Beijing 100029, P. R. China

\section{Notes}

The authors declare no competing financial interest.

\section{ACKNOWLEDGMENTS}

We gratefully acknowledge financial support from the EPSRC for funding (grants EP/L023652/1, EP/K023004/1, EP/ $\mathrm{H} 024107 / 1$, EP/I033459/1, and EP/J015156/1), the University of Glasgow, and the ERC (project 670467 SMART-POM). L.C. thanks the Royal-Society Wolfson Foundation for a Merit Award. We also thank Dr. Ross Winter for useful comments on the manuscript.

\section{REFERENCES}

(1) Long, J. R., Yaghi, O. M., Eds. Metal Organic Frameworks [Special Issue]. Chem. Soc. Rev. 2009, 38, 1201-1508.

(2) Meek, S. T.; Greathouse, J. A.; Allendorf, M. D. Adv. Mater. 2011, 23, 249-267.

(3) Jiang, J.; Zhao, Y.; Yaghi, O. M. J. Am. Chem. Soc. 2016, 138, 3255-3265.

(4) Mastalerz, M. Angew. Chem., Int. Ed. 2008, 47, 445-447.

(5) Vermeiren, W.; Gilson, J.-P. Top. Catal. 2009, 52, 1131-1161.

(6) Taarning, E.; Osmundsen, C. M.; Yang, X.; Voss, B.; Andersen, S. I.; Christensen, C. H. Energy Environ. Sci. 2011, 4, 793-804.

(7) Wang, S.; Peng, Y. Chem. Eng. J. 2010, 156, 11-24.

(8) Olguín, M. T.; Deng, S. J. Hazard. Mater. 2016, 302, 341-350.

(9) Shao, D. D.; Fan, Q. H.; Li, J. X.; Niu, Z. W.; Wu, W. S.; Chen, Y. X.; Wang, X. K. Microporous Mesoporous Mater. 2009, 123, 1-9.

(10) Lew, C. M.; Cai, R; Yan, Y. Acc. Chem. Res. 2010, 43, 210-219.

(11) Chen, C. H.; Li, S.-Y.; Chiang, A. S. T.; Wu, A. T.; Sun, Y. S. Sol. Energy Mater. Sol. Cells 2011, 95, 1694-1700.

(12) Čejka, J.; Van Bekkum, H.; Corma, A.; Schüth, F. Introduction to Zeolite Science and Practice; Elsevier: Amsterdam, 2007. 
(13) Masters, A. F.; Maschmeyer, T. Microporous Mesoporous Mater. 2011, 142, 423-438.

(14) Kawano, M.; Fujita, M. Coord. Chem. Rev. 2007, 251, 25922605.

(15) Kawamichi, T.; Haneda, T.; Kawano, M.; Fujita, M. Nature 2009, 461, 633-635.

(16) Sun, J.; Zou, X. Dalton Trans. 2010, 39, 8355-8362.

(17) O'Brien, M. G.; Beale, A. M.; Weckhuysen, B. M. Chem. Soc. Rev. 2010, 39, 4767-4782.

(18) Bordiga, S.; Bonino, F.; Lillerud, K. P.; Lamberti, C. Chem. Soc. Rev. 2010, 39, 4885-4927.

(19) Verboekend, D.; Pérez-Ramírez, J. Catal. Sci. Technol. 2011, 1, 879-890.

(20) Wang, Z.; Yu, J.; Xu, R. Chem. Soc. Rev. 2012, 41, 1729-1741.

(21) Park, K. S.; Ni, Z.; Côté, A. P.; Choi, J. Y.; Huang, R.; UribeRomo, F. J.; Chae, H. K.; O’Keeffe, M.; Yaghi, O. M. Proc. Natl. Acad. Sci. U. S. A. 2006, 103, 10186-10191.

(22) Phan, A.; Doonan, C. J.; Uribe-Romo, F. J.; Knobler, C. B.; O’Keeffe, M.; Yaghi, O. M. Acc. Chem. Res. 2010, 43, 58-67.

(23) Yaghi, O. M.; O’Keeffe, M.; Ockwig, N. W.; Chae, H. K.; Eddaoudi, M.; Kim, J. Nature 2003, 423, 705-714.

(24) Ockwig, N. W.; Delgado-Friedrichs, O.; O’Keeffe, M.; Yaghi, O. M. Acc. Chem. Res. 2005, 38, 176-182.

(25) Cheetham, A. K.; Rao, C. N. R.; Feller, R. K. Chem. Commun. 2006, 4780-4795.

(26) Tranchemontagne, D. J.; Mendoza-Cortés, J. L.; O’Keeffe, M.; Yaghi, O. M. Chem. Soc. Rev. 2009, 38, 1257-1283.

(27) Hill, C. L., Ed. Polyoxometalates [Special Issue]. Chem. Rev. 1998, 98, 1-390.

(28) Oms, O.; Dolbecq, A.; Mialane, P. Chem. Soc. Rev. 2012, 41, 7497-7536.

(29) Long, D.-L.; Tsunashima, R.; Cronin, L. Angew. Chem., Int. Ed. 2010, 49, 1736-1758.

(30) Streb, C.; Ritchie, C.; Long, D.-L.; Kögerler, P.; Cronin, L. Angew. Chem., Int. Ed. 2007, 46, 7579-7582.

(31) Ritchie, C.; Streb, C.; Thiel, J.; Mitchell, S. G.; Miras, H. N.; Long, D.-L.; Boyd, T.; Peacock, R. D.; McGlone, T.; Cronin, L. Angew. Chem., Int. Ed. 2008, 47, 6881-6884.

(32) Marleny Rodriguez-Albelo, L.; Ruiz-Salvador, A. R; Sampieri, A.; Lewis, D. W.; Gómez, A.; Nohra, B.; Mialane, P.; Marrot, J.; Sécheresse, F.; Mellot-Draznieks, C.; Biboum, R. N.; Keita, B.; Nadjo, L.; Dolbecq, A. J. Am. Chem. Soc. 2009, 131, 16078-16087.

(33) Wang, X.-L.; Hu, H.-L.; Tian, A.-X. Cryst. Growth Des. 2010, 10, $4786-4784$.

(34) Wang, Y.; Ye, L.; Wang, T.-G.; Cui, X.-B.; Shi, S.-Y.; Wang, G.W.; Xu, J.-Q. Dalton Trans. 2010, 39, 1916-1919.

(35) Zhan, C.; Cameron, J. M.; Gabb, D.; Boyd, T.; Winter, R. S.; Vilà-Nadal, L.; Mitchell, S. G.; Glatzel, S.; Breternitz, J.; Gregory, D. H.; Long, D.-L.; Macdonell, A.; Cronin, L. Nat. Commun. 2017, 8, 14185-14191.

(36) Thiel, J.; Ritchie, C.; Miras, H. N.; Streb, C.; Mitchell, S. G.; Boyd, T.; Ochoa, M. N. C.; Rosnes, M. H.; McIver, J.; Long, D.-L.; Cronin, L. Angew. Chem., Int. Ed. 2010, 49, 6984-6988.

(37) Férey, G.; Mellot-Draznieks, C.; Serre, C.; Millange, F.; Dutour, J.; Surble, S.; Margiolaki, I. Science 2005, 309, 2040-2042.

(38) Ma, F.-J.; Liu, S.-X.; Sun, C.-Y.; Liang, D.-D.; Ren, G.-J.; Wei, F.; Chen, Y.-G.; Su, Z.-M. J. Am. Chem. Soc. 2011, 133, 4178-4181.

(39) Song, J.; Luo, Z.; Britt, D.-K.; Furukawa, H.; Yaghi, O. M.; Hardcastle, K. I.; Hill, C. L. J. Am. Chem. Soc. 2011, 133, 1683916846.

(40) Bromberg, L.; Hatton, T. A. ACS Appl. Mater. Interfaces 2011, 3, $4756-4764$.

(41) Dolbecq, A.; Sécheresse, F. Adv. Inorg. Chem. 2002, 53, 1-40.

(42) Contant, R.; Tézé, A. Inorg. Chem. 1985, 24, 4610-4614.

(43) Keita, B.; Lu, Y. W.; Nadjo, L.; Contant, R. Electrochem. Commun. 2000, 2, 720-726.

(44) Sing, K. S. W.; Everett, D. H.; Haul, R. A. W.; Moscou, L.; Pierotti, R. A.; Rouquérol, J.; Siemieniewska, T. Pure Appl. Chem. 1985, 57, 603-619.
(45) Mitchell, S. G.; Gabb, D.; Ritchie, C.; Hazel, N.; Long, D.-L.; Cronin, L. CrystEngComm 2009, 11, 36-39.

(46) Zhang, L. C.; Xue, H.; Zhu, Z.-M.; Zhang, Z.-M.; Li, Y.-G.; Wang, E.-B. J. Cluster Sci. 2010, 21, 679-689.

(47) Zimmermann, M.; Belai, N.; Butcher, R. J.; Pope, M. T.; Chubarova, E. V.; Dickman, M. H.; Kortz, U. Inorg. Chem. 2007, 46, 1737-1740.

(48) Contant, R. In Inorganic Syntheses; Ginsberg, A. P., Ed.; John Wiley \& Sons: New York, 1990; pp 110-111.

(49) Boyd, T.; Mitchell, S. G.; Gabb, D.; Long, D.-L.; Cronin, L. Chem. - Eur. J. 2011, 17, 12010-12014.

(50) Mal, S. S.; Nsouli, N. H.; Dickman, M. H.; Kortz, U. Dalton Trans. 2007, 2627-2630.

(51) Mitchell, S. G.; Streb, C.; Miras, H. N.; Boyd, T.; Long, D.-L.; Cronin, L. Nat. Chem. 2010, 2, 308-312.

(52) Chen, S.-W.; Boubekeur, K.; Gouzerh, P.; Proust, A. J. Mol. Struct. 2011, 994, 104-108.

(53) Bassil, B. S.; Ibrahim, M.; Mal, S. S.; Suchopar, A.; Biboum, R. N.; Keita, B.; Nadjo, L.; Nellutla, S.; Van Tol, J.; Dalal, N. S.; Kortz, U. Inorg. Chem. 2010, 49, 4949-4959.

(54) Mitchell, S. G.; Boyd, T.; Miras, H. N.; Long, D.-L.; Cronin, L. Inorg. Chem. 2011, 50, 136-143.

(55) Jiang, J.; Yu, J.; Corma, A. Angew. Chem., Int. Ed. 2010, 49, $3120-3145$. 